\title{
Differences in genome-wide gene expression response in peripheral blood mononuclear cells between young and old men upon caloric restriction
}

\author{
I. P. G. Van Bussel' ${ }^{1}$ A. Jolink-Stoppelenburg ${ }^{1}$, C. P. G. M. De Groot ${ }^{1}$, M. R. Müller ${ }^{1,2}$ and L. A. Afman ${ }^{1,3^{*}}$
}

\begin{abstract}
Background: Caloric restriction (CR) is considered to increase lifespan and to prevent various age-related diseases in different nonhuman organisms. Only a limited number of CR studies have been performed on humans, and results put $C R$ as a beneficial tool to decrease risk factors in several age-related diseases. The question remains at what age CR should be implemented to be most effective with respect to healthy aging. The aim of our study was to elucidate the role of age in the transcriptional response to a completely controlled $30 \%$ CR diet on immune cells, as immune response is affected during aging. Ten healthy young men, aged 20-28, and nine healthy old men, aged 64-85, were subjected to a 2-week weight maintenance diet, followed by 3 weeks of $30 \%$ CR. Before and after $30 \% \mathrm{CR}$, the whole genome gene expression in peripheral blood mononuclear cells (PBMCs) was assessed.
\end{abstract}

Results: Expression of 554 genes showed a different response between young and old men upon CR. Gene set enrichment analysis revealed a downregulation of gene sets involved in the immune response in young but not in old men. At baseline, immune response-related genes were higher expressed in old compared to young men. Upstream regulator analyses revealed that most potential regulators were controlling the immune response.

Conclusions: Based on the gene expression data, we theorise that a short period of $C R$ is not effective in old men regarding immune-related pathways while it is effective in young men.

Trial registration: ClinicalTrials.gov, NCT00561145

Keywords: Age, Caloric restriction, Gene expression, Microarray, Peripheral blood mononuclear cells

\section{Background}

Caloric restriction $(\mathrm{CR})$, the restriction of food intake without malnutrition, increases longevity in Caenorhabditis elegans [31], Saccharomyces cerevisiae [18], and rodents [32]. In addition to longevity, CR minimises the age-related dysfunction of organs [19] and lowers risks of several age-related diseases, for example, cancer in rats and mice [22], and age-related aorta sclerosis in rats [4]. CR studies in primates led to less conclusive results.

\footnotetext{
* Correspondence: lydia.afman@wur.nl

'Division of Human Nutrition, Wageningen University, Bomenweg 2, 6703 HD Wageningen, The Netherlands

${ }^{3}$ Division of Human Nutrition, Wageningen University \& Research centre, PO BOX 8129, NL-6700 EV Wageningen, The Netherlands

Full list of author information is available at the end of the article
}

CR did increase longevity in monkeys at the Wisconsin National Primate Research Centre [6] but did not increase longevity in monkeys at the National Institute of Aging [20]. Factors such as genetics, husbandry, or dietary composition are perhaps more relevant for longevity in these primate studies than the number of calories [20]. Despite contrasting longevity results, both studies documented beneficial health effects of $\mathrm{CR}$, including improved immune function and improved glucose homeostasis [20]. The limited number of studies investigating the effect of a CR diet in humans is, because of long life expectancy [27], solely directed at beneficial health effects and not at longevity [15]. For example, 6 years of CR decreased risk factors for atherosclerosis 
in humans [11] and 1 year of CR decreased risk factors for coronary heart disease in humans [12]. Also, aging processes seem to be altered by CR: the gene expression profiles from skeletal muscles from humans of the $\mathrm{CR}$ Society showed a closer relationship to the gene expression profiles of young subjects than to those of agematched subjects [21]. The preventive or retardative effect of CR on age-associated changes in gene expression has also been shown in the muscle, brain, heart, and adipose tissue from other species [23].

Mechanisms underlying beneficial effects of CR remain largely unclear. To understand these mechanisms, genes and molecular pathways involved in the effects of $\mathrm{CR}$ on longevity and healthy aging have been investigated. Overall, the effects of $\mathrm{CR}$ are characterised by the downregulated expression of genes involved in growth hormone signalling and genes involved in immune response [25]. In contrast, aging is characterised by the upregulated expression of genes involved in immune response [10]. The opposing effects of $\mathrm{CR}$ and aging on the immune response might be one potential lead for the beneficial effects of CR on healthy aging. In this regard, immune cells, such as peripheral blood mononuclear cells (PBMCs), are an interesting target to study in humans $[13,25]$. PBMCs are easily accessible and circulate in the blood [2], exposing them to metabolites, hormones, chemokines, or cytokine from tissues such as the liver and adipose tissue [3], which make them relevant to study. So far, most human $\mathrm{CR}$ studies have been executed in middle-aged subjects; the question remains at what age CR should be implemented to be most effective with respect to healthy aging. To approach this question, we aimed to elucidate the effect of age in the response to $C R$ by comparing whole genome gene expression response to 3 weeks of 30 \% CR in PBMCs from old and young men.

\section{Results}

Baseline characteristics for ten young and nine old men of which high quality microarrays were present are summarised in Table 1. Besides the lower body mass index

Table 1 Baseline characteristics of young $(n=10)$ and old $(n=$ 9) men of whom microarray analysis on PBMCs was performed. Data represent mean and (SD) or median and [range]

\begin{tabular}{llll}
\hline & Young men & Old men & $P$ value \\
\hline Age $($ year $)$ & $24[20,28]$ & $70[64,85]$ & $4.37 \mathrm{E}-09$ \\
Height $(\mathrm{m})$ & $1.78(0.06)$ & $1.77(0.04)$ & $5.26 \mathrm{E}-01$ \\
Weight $(\mathrm{kg})$ & $71.1(8.52)$ & $76.7(7.4)$ & $1.28 \mathrm{E}-01$ \\
Body mass index $\left(\mathrm{kg} / \mathrm{m}^{2}\right)$ & $22.4(2.3)$ & $24.6(2.0)$ & $3.08 \mathrm{E}-02$ \\
Glucose $(\mathrm{mmol} / \mathrm{L})$ & $4.5[3.7,5.1]$ & $5.2[4.8,5.5]$ & $5.17 \mathrm{E}-04$ \\
Haemoglobin $(\mathrm{g} / \mathrm{L})$ & $9.4(0.4)$ & $9.3(0.4)$ & $5.69 \mathrm{E}-01$ \\
Haematocrit $(\%)$ & $45(2)$ & $44(2)$ & $5.46 \mathrm{E}-1$ \\
\hline
\end{tabular}

(BMI, $P=0.04)$ and lower fasting glucose level $(P<0.001)$ in old compared to young men, no differences were observed.

Three weeks of CR resulted in a decrease in body weight and BMI in both groups (Table 2). Age had no effect on weight $(P=0.18)$ or BMI change $(P=0.18)$.

\section{Effect on gene expression: old versus young}

At baseline, before $30 \%$ CR, 696 genes were significantly differently expressed between old and young men (Fig. 1a). To identify the effect of age on CR-induced gene expression changes, responses to $\mathrm{CR}$ were compared between old and young men (Fig. 1b). A total of 554 genes showed a significantly different expression response between old and young men.

\section{Effect of CR on gene expression: pathway analysis}

Gene Set Enrichment Analysis (GSEA) was used to identify pathways in which gene expression was differentially regulated by age, at baseline, or in response to CR. Before the start of the $30 \% \mathrm{CR}$ diet, the expression of genes involved in immune response was higher in old compared to young men and the expression of genes involved in RNA processing was lower in old compared to young men (Table 3). Upon 3 weeks of $30 \%$ CR, the expression of genes involved in immune response and glucose metabolism was downregulated in young men only, whereas the expression of genes involved in olfactory signalling was downregulated in old men only.

\section{Upstream regulator analysis}

Ingenuity Pathway Analysis (IPA) Upstream Regulator Analysis is a tool to find transcription regulators that may explain the observed gene expression. To identify these upstream regulators of genes that had a different expression before CR between old and young, or had a changed expression upon $\mathrm{CR}$, we performed IPA Upstream Regulator Analysis. The regulators that were predicted to be affected at baseline and upon $\mathrm{CR}$ are listed in Additional file 1: Table S1. This list shows immune-related upstream regulators, interferon lambda 1 (INFL1), interferon alpha 2 (IFNA2), and interferon gamma (IFNG), that were predicted to be significantly higher in old compared to young before intervention. IFNA2 and IFNG were inhibited upon $\mathrm{CR}$ in young men, but not in old men. To identify correlation between the genes predicted to be regulated, we selected all significantly changed genes targeted by the predicted transcriptional regulators upon $\mathrm{CR}$ and created correlation heat maps of the significant changes in expression of these genes for young men (Fig. 2 (A1)) and old men (Fig. 2 (A2)). For young men, 57 unique genes were affected by the six identified transcriptional regulators, i.e. IFNA2, IFNG, 
Table 2 Body weight and body mass index of young and old men before and upon 3 weeks of $30 \%$ CR and significance ( $P$ value). Data represent mean with (SD)

\begin{tabular}{|c|c|c|c|c|}
\hline & & Before CR & Upon CR & $P$ value \\
\hline \multirow[t]{2}{*}{ Weight (kg) } & Young $(n=10)$ & $71.1(8.5)$ & $68.7(8.6)$ & $2.87 \mathrm{E}-05$ \\
\hline & Old $(n=9)$ & $76.7(7.4)$ & $74.9(7.4)$ & $6.53 \mathrm{E}-05$ \\
\hline \multirow[t]{2}{*}{ Body mass index $\left(\mathrm{kg} / \mathrm{m}^{2}\right)$} & Young $(n=10)$ & $22.4(2.3)$ & $21.6(2.3)$ & $3.64 \mathrm{E}-05$ \\
\hline & Old $9(n=9)$ & $24.6(2.0)$ & $24.0(2.0)$ & $4.21 \mathrm{E}-05$ \\
\hline
\end{tabular}

eukaryotic translation initiation factor 2-alpha kinase 2 (EIF2AK2), mitogen-activated protein kinase 1 (MAPK1), glyceraldehyde-2-phosphate dehydrogenase (GAPDH), and transglutaminase 2 (TGM2) (Additional file 1: Table S1). These genes showed a distinct correlation in young men (Fig 2 (A1)) which was less strong or absent in old men (Fig 2 (A2)). Contrary for old men, many genes regulated by the upstream regulators were overlapping: 15 potential upstream regulators

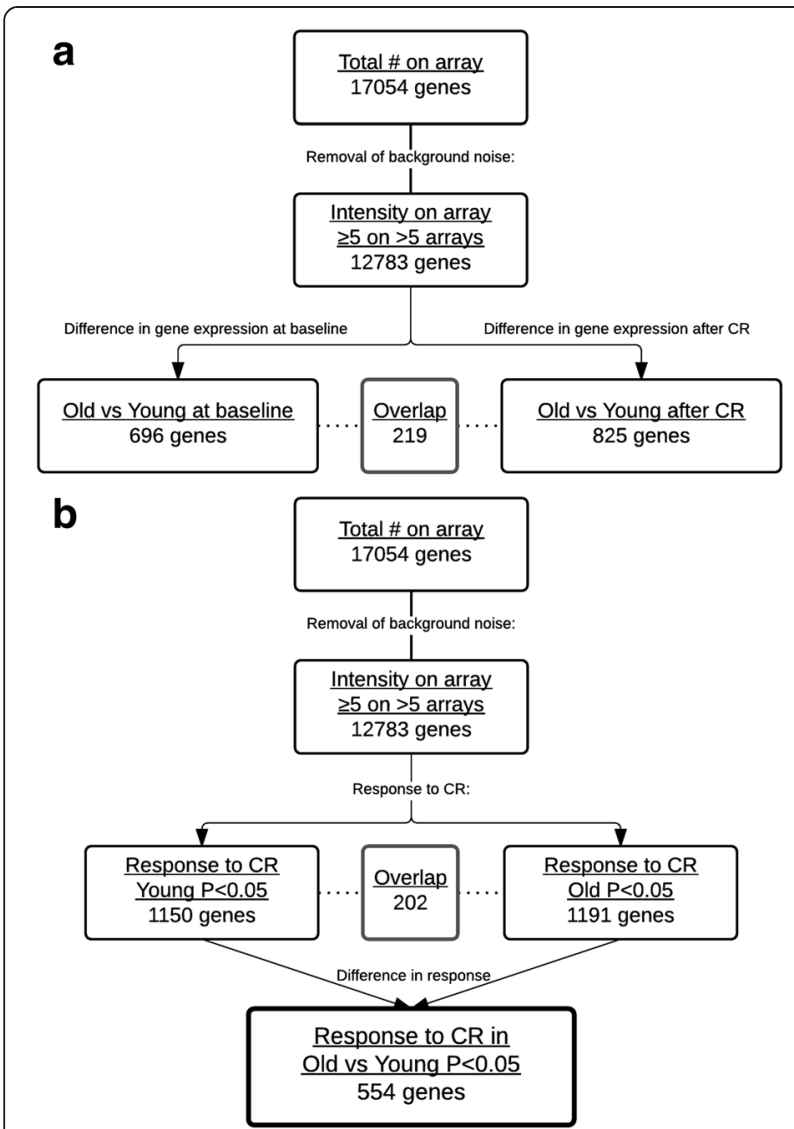

Fig. 1 Stepwise selection of genes in microarray analysis of old versus young men upon 3 weeks of $30 \%$ CR: 12,783 genes were selected for signal intensity ( $\geq 5$ in $>5$ arrays), a for a difference in expression between old and young $(P<0.05)$ men at baseline (left track) and upon CR (right track), and $\mathbf{b}$ a change in expression of genes for young (left track) and old (right track) in response to CR. The last box depicts the number of genes that has a different response to $C R$ in old versus young men
(Additional file 1: Table S1) were predicted to affect 17 unique genes, and no specific correlation pattern for old could be identified (Fig. 2 (B)).

\section{Younger transcriptional profile upon $\mathrm{CR}$}

To identify if old men were able to obtain, at least for a subset of genes, a younger gene expression profile upon $\mathrm{CR}$, the following approach was used: selection of genes with a different expression between old and young before CR resulting in 696 genes (Fig. 3); 96 of these genes also showed a significant different response upon CR between old and young men (Fig. 3); 55 of these genes had a changed expression in old men only. Figure 4 shows a heat map of the gene expression per subject and illustrates the different expressed genes at baseline and the change towards a young profile in old men, as is shown by the third part of the heat map where no significant expression differences between old and young upon $\mathrm{CR}$ were present.

\section{Discussion}

We aimed to investigate the potential relevance of age at which $\mathrm{CR}$ should be implemented to be most effective on gene expression changes of pathways important for healthy aging. To achieve this, we compared the gene expression changes in PBMCs of old men with the gene expression changes in PBMCs of young men upon 3 weeks of $30 \%$ CR.

Three weeks of $\mathrm{CR}$ resulted in a downregulated expression of genes involved in immune response and glucose metabolism in young but not in old men. Effects

Table 3 Pathways changed in PBMC gene expression profiles of young and old men before and upon 3 weeks of $30 \%$ CR

\begin{tabular}{llll}
\hline Pathway & Baseline (old vs young) & Young men & Old men \\
\hline RNA processing & $\downarrow$ & $\uparrow$ & $\uparrow$ \\
Cell cycle & - & $\uparrow / \downarrow^{\mathrm{a}}$ & $\uparrow /$ - $^{\mathrm{a}}$ \\
Oxidative stress & - & $\downarrow$ & $\downarrow$ \\
Immune response & $\uparrow$ & $\downarrow$ & - \\
Glucose metabolism & - & $\downarrow$ & - \\
Olfactory signalling & - & - & $\downarrow$ \\
\hline
\end{tabular}

$\downarrow$ downregulated, $\uparrow$ upregulated, - no change

${ }^{\text {aPart }}$ of gene sets classified under these pathways were upregulated, whereas others where downregulated 


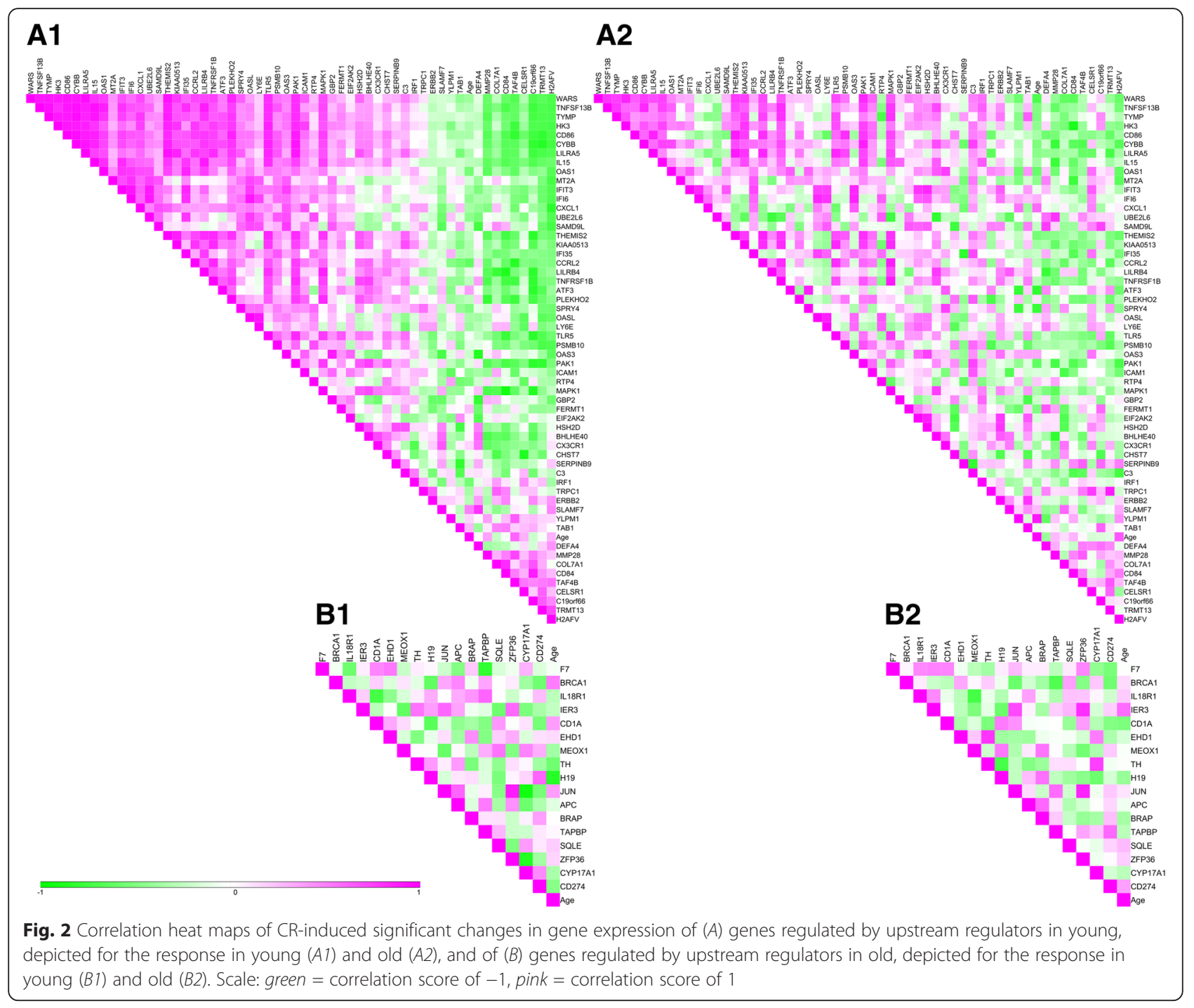

of $\mathrm{CR}$ on immune response-related gene expression have been shown before; 8 weeks of CR in middle-aged obese men downregulated the expression of genes involved in immune response in PBMCs [7]. The response of these middle-aged obese men is similar to the response of young men in our study. One reason why we do not see the response in old men might be due to 'immunosenescence' [24], known to take place in elderly individuals above 65 years of age. Immunosenescence means the loss of immune functions and is characterised by an increase in the expression of inflammation- and immune response-related genes [10]. Although the overlap between the genes in this paper and in the current study is minimal, we also observed an increase in gene expression and a predicted activation of transcriptional regulators involved in immune pathways, i.e. IFNA2 and IFNG, in old men at baseline when compared to young. Upon CR, a decreased activation of IFNA2 and IFNG was only observed in young men. MAPK1 was activated upon CR. MAPK1 represses the expression of IFNGinduced genes via DNA-binding [16]. An increase in MAPK1 might have affected the decrease in IFNGinduced genes. The potential immunosenescence present at baseline may be the reason why we do not see a response on immune-related pathways upon CR in the old men. This is further illustrated by the correlation heat maps of immune-related genes in which high correlations are observed between gene expression responses in young men and far less pronounced effects are observed in old men. Old men seem to have lost the ability to change gene expression in immune response upon $\mathrm{CR}$. This inability to change expression might be due to a potential advanced aging-related state of epigenetics, keeping the DNA structure in a more rigid structure and making it less likely to change gene expression. Either 3 weeks of $30 \%$ CR is not sufficient to reduce the higher gene expression of immune-related genes in old men or the age-related potential epigenetic changes are 


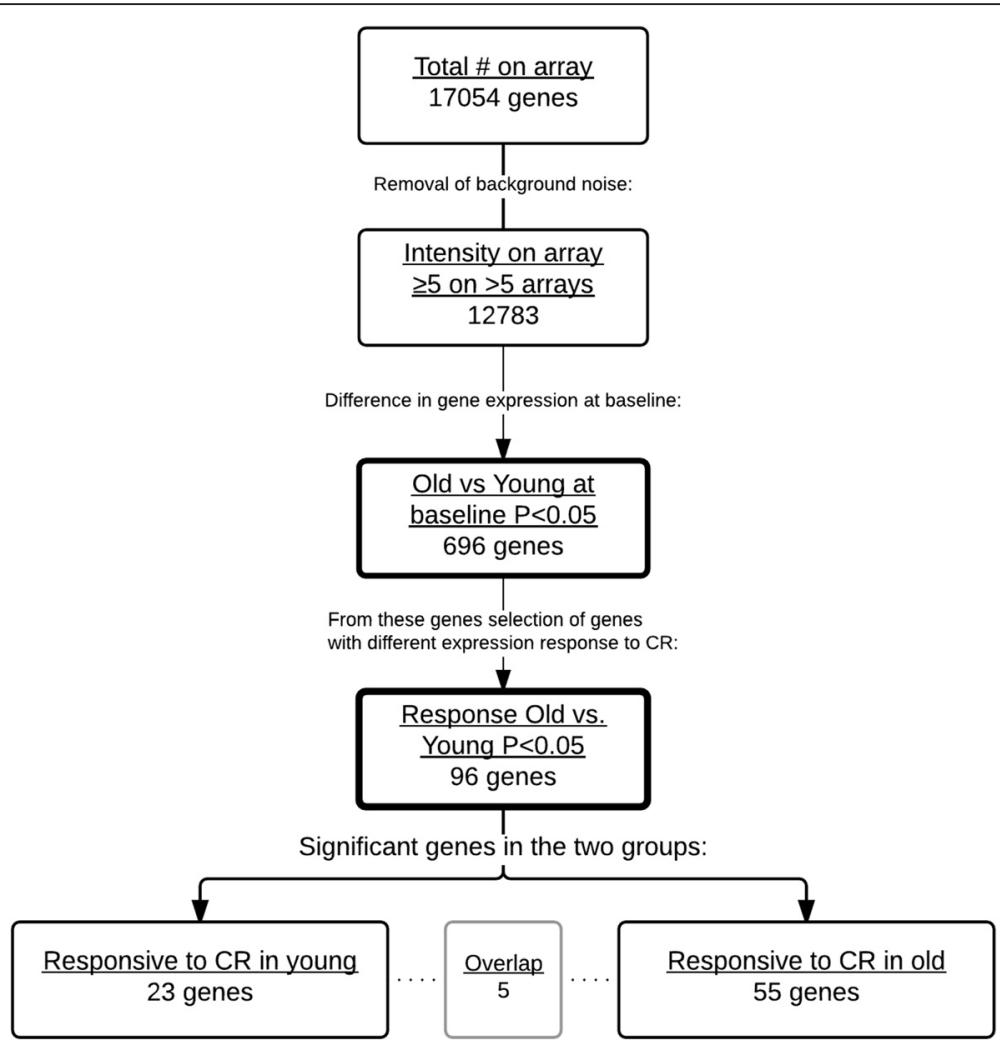

Fig. 3 Stepwise selection of genes in microarray analysis to identify genes in which expression changed from an old profile to a young profile upon 3 weeks of $30 \%$ CR. For signal intensity, 12,783 genes were selected ( $\geq 5$ in $>5$ arrays); from these, 96 genes were selected that were differently expressed between old and young men before $C R(P<0.05)$; the last part depicts number of genes that show a different response to $C R$ in old versus young men. Finally, 23 genes with a significant change in expression within young (left track) men and 55 genes within old (right track) men are shown

too strong to overcome with $\mathrm{CR}$ and $\mathrm{CR}$ should be started at an earlier age. Three weeks of CR also resulted in a downregulated expression of genes involved in glucose metabolism in young men only. We did not find a difference in the expression of genes involved in glucose metabolism at baseline between old and young men, even though aging is known to have a diminishing effect on adequate glucose metabolism [9]. Aging might, however, have played a role in the nonresponsive effect of our short-term CR on glucose metabolism-related pathways in old men.

The decreased expression of genes related to olfactory signalling pathways in old men has not been described in the literature. However, other studies in fruit flies have been done in which the absence of odorants from nutrients affected the expression of odorant-binding proteins [26]. In addition, it has been described before in yeast that $\mathrm{CR}$ has an increasing effect on the expression of genes involved in RNA processing [5] as seen in our study for both young and old men.

Although old men did not respond with the same changes on immune response and glucose metabolism, many genes did show a change in expression upon CR. We identified a group of genes that changed from an 'old' expression level towards a 'young' expression level upon
CR. This was in line with the finding that the expression of genes from the skeletal muscle tissue of middle-aged subjects of the Caloric Restriction Society matched closer to gene expression profiles of younger subjects than to gene expression profiles of age-matched controls [21]. We could, however, not find any clear signalling route, pathway, or network for these genes.

It should be mentioned that both baseline differences and differences in gene expression changes between young and old can be due to different subpopulations of immune cells in the PBMCs between the groups. During aging, involution of the thymus, responsible for production of naïve $\mathrm{T}$ cells, leads to a shift in the $\mathrm{T}$ cell population [14]. Unfortunately, we did not have the opportunity to determine PBMC subpopulations. Furthermore, a period of 3 weeks of CR is short and might not have been long enough to induce changes in the gene expression of old men. A strength of our study design is the completely controlled dietary run-in period of 2 weeks and the completely controlled dietary $30 \%$ CR intervention of 3 weeks which excludes a potential effect of habitual diet differences between the young and old men on gene expression differences at baseline and on gene expression response upon CR. 


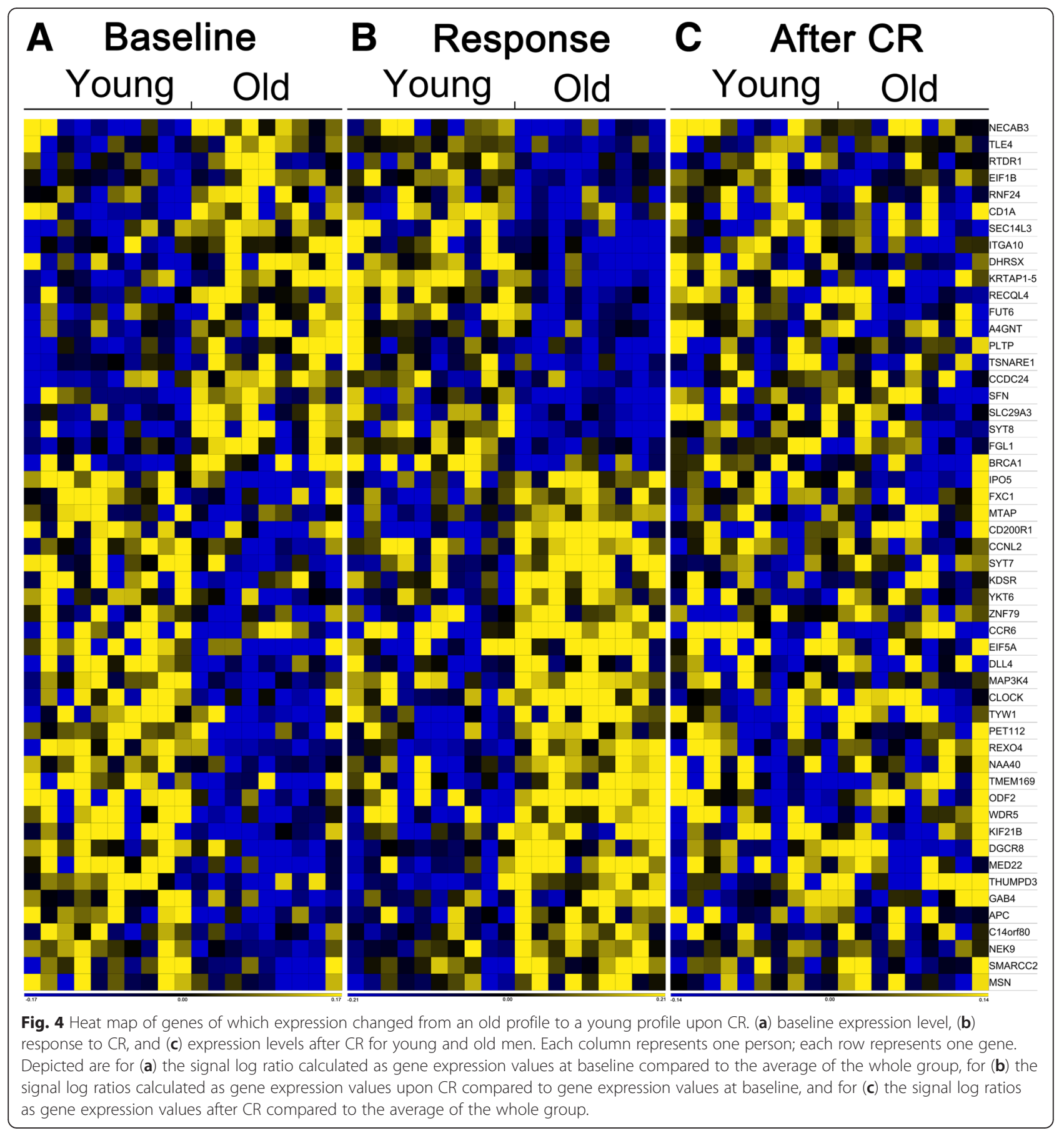

\section{Conclusions}

In our study, the expression of genes involved in immune response pathways was higher in old compared to young men at baseline. Three-week $30 \%$ CR did not affect this higher immune-related gene expression in old men whereas it did reduce immune-related gene expression in young men. Due to our small sample size, we cannot draw solid conclusions about the relevance of age on the effect of $\mathrm{CR}$ on gene expression changes of pathways important for healthy aging. We hypothesise based on immune-related gene expression changes in men that for a short period of $30 \% \mathrm{CR}$ a young onset has more potential benefit than an old onset.

\section{Methods}

Study population and eligibility criteria

Our study population was a subgroup of participants who participated in a previously reported controlled-feeding 
trial [34]. Male Caucasian participants were recruited, by publishing advertisements in local newspapers and by sending out general e-mails to an e-mail list of persons who had indicated their interest in participating in studies of our university, at Wageningen University (The Netherlands), in October 2007 till January 2008, and followed up until the 15th of March 2008. Participants were excluded based on the following criteria: body mass index (BMI, $\mathrm{kg} / \mathrm{m}^{2}$ ) less than 20 or higher than 30 , adherence to a weight-reduction or medically prescribed diet, dementia (Mini-Mental State Examination score <21), diabetes, anaemia, gastrointestinal disorders, use of drugs known to interfere with energy balance, or a history of medical or surgical events known to affect the study outcome. Participants were divided based on their age into young (20-40 years) and old (65-85 years) men. Based on these criteria, 15 young and 17 old men were included in the original study at Wageningen University (The Netherlands) [34]. Microarray analyses were performed on high-quality PBMC RNA of ten young men, age range $20-28$ years, and nine old men, age range 64-85 years (Fig. 5).

Each of the participants was informed about the design and purpose of the study, and each of the participants provided written informed consent. The Medical Ethical Committee of Wageningen University (The Netherlands) approved the study. This clinical study was registered with ClinicalTrials.gov as NCT00561145.

\section{Study design}

The original study consisted of three subsequent phases as described previously [34] and was all carried out at the Division of Human Nutrition of Wageningen University (The Netherlands). Only samples collected after phases 1 and 2 are the subject of the current paper. Phase 1 (days 1-14): controlled dietary intervention in which each of the participants had to remain weight stable. Each of the participants was provided with a diet containing approximately $90 \%$ of their estimated total daily energy requirement. The remaining $10 \%$ was chosen from a list of choice items. In phase 2 (days 15-35): each of the participants was provided with a diet containing $70 \%$ of the energy consumed during the last 3 days of phase 1. Composition of the diets was determined as described in [34]. Blood samples were taken at the end of phase 1, before $\mathrm{CR}$, and at the end of phase 2, after CR.

\section{PBMC RNA isolation and microarray processing}

PBMCs were isolated from whole blood using $B D$ Vacutainer ${ }^{\circ}$ Cell Preparation Tubes ${ }^{\mathrm{Tm}}$ according to the manufacturer's instructions. Total RNA was isolated from PBMC samples using TRIzol reagent (Invitrogen, Breda, The Netherlands) and purified using Qiagen RNeasy Micro Kit (Qiagen, Venlo, The Netherlands). RNA integrity was checked with Agilent 2100 Bioanalyzer (Agilent Technologies, Amstelveen, The Netherlands). Total RNA (500 ng/sample) was labelled using a one-cycle cDNA labelling kit (MessageAmpTM II-Biotin Enhanced Kit; Ambion Inc., Nieuwerkerk aan de IJssel, The Netherlands) and hybridised to human whole genome GeneChip arrays encoding 17,054 genes, designed by the European Nutrigenomics Organization and manufactured by Affymetrix (Santa Clara, CA). Sample labelling, hybridization to chips, and image scanning were performed according to the manufacturer's instructions.

\section{Microarray data analysis}

Quality control was performed and fulfilled the criteria for array hybridisation suggested by the Tumor Analysis Best Practices Working Group [30].

Microarrays were analysed using reorganised oligonucleotide probes as described by Dai et al. [8]. All individual probes for a gene were combined, allowing the

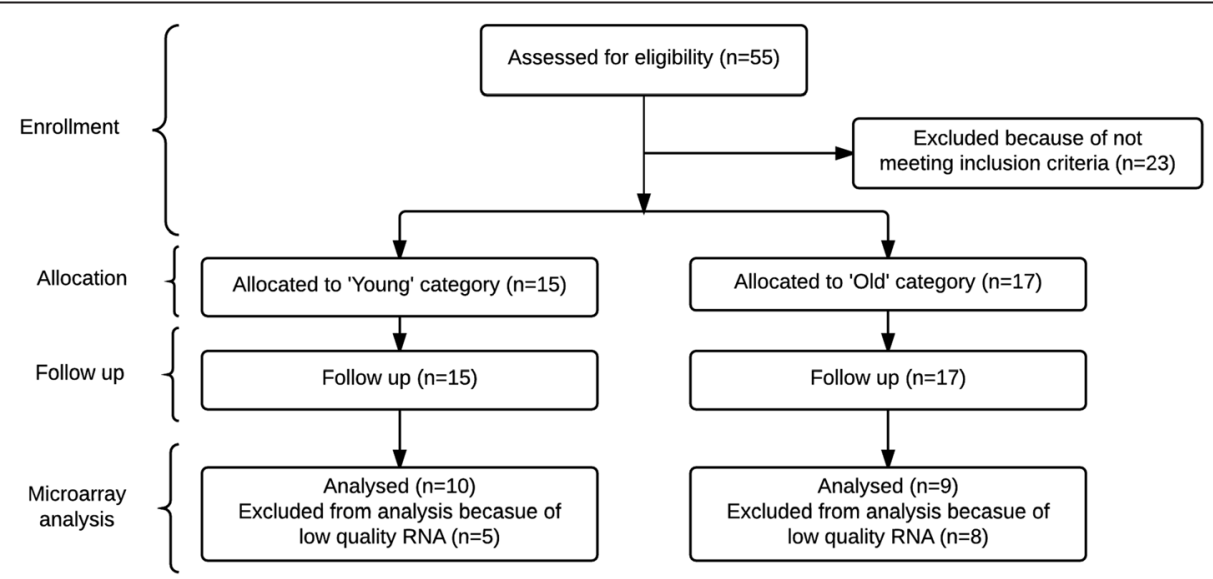

Fig. 5 Flow diagram of subject inclusion 
possibility to detect overall transcription activity on the basis of latest genome and transcriptome information, rather than on the basis of Affymetrix probe set annotation. Expression values were calculated with the Robust Multi-array Average (RMA) method and quantile normalised [1, 17]. Only probe sets with normalised signals $>5$ on $\geq 5$ arrays were defined as expressed and selected for analysis. This normalisation level was chosen because of a low microarray intensity level, due to the use of expired microarrays. It has, however, been shown that microarray data generated by microarrays more than 4 years past the manufacturer's expiration date had lower signal intensities but were highly specific and consistent with those from unexpired microarrays [33]. We used microarrays within 2 years of the expiry date.

Individual genes were defined as changed when comparison of the average normalised signal intensities showed a $P$ value $<0.05$ in a two-tailed paired $t$ test with Bayesian correction (Limma) [29]. Filtered data were analysed with Gene Set Enrichment Analysis (GSEA; GSEA/ MSigDB website v3.87 released April 4, 2013). Significantly regulated gene sets were defined with a false discovery rate of $<0.25$. Gene sets were visualised and clustered using Cytoscape [28], which enabled the identification of clusters of gene sets. Ingenuity Pathway Analysis version 8.5 (Ingenuity Systems, Redwood City, CA) was also used for pathway analysis and upstream regulator analysis, but because of similar results, only GSEA results are displayed. Ingenuity Pathway Analysis has been performed based on findings from human experiments.

For upstream regulator analysis at baseline, genes with a significant different expression at baseline were included $(P$ $<0.05)$. For young, genes with a significant different response upon $\mathrm{CR}$ in young were included $(P<0.05)$, and for old, genes with a significant different response upon $\mathrm{CR}$ in old were included $(P<0.05)$. For correlation heat maps, target genes of the upstream regulators were included if they also had a significantly different response between old and young $(P<0.05)$ upon CR. Array data have been submitted to Gene Expression Omnibus under accession number GSE63117.

\section{Statistical analysis of clinical measurements}

The statistical package SPSS (version 15.0; SPSS Inc, Chicago, IL) was used for analysis of the following data: expression changes within age groups were determined by paired $t$ tests, and differential changes between age groups were determined by unpaired $t$ tests.

\section{Availability of supporting data}

The data set supporting the results of this article is available in the Gene Expression Omnibus repository, under accession number GSE63117, at http://www.ncbi.nlm.nih.gov/ geo/. Additional data can be found in supplemental files. Additional file 2 contains the Quality Control report,
Additional file 3 contains gene expression analysis, Additional file 4 contains GSEA outputs, and Additional file 5 contains IPA outputs.

\section{Additional files}

Additional file 1: Table S1. Predicted upstream regulators. Predicted difference before CR between old and young, in the response of young, the response in old, and the difference upon CR between old and young. (PDF 106 kb)

Additional file 2: Complete quality control report of microarrays. (PDF $3939 \mathrm{~kb}$ )

Additional file 3: Gene expression file with expression analysis (A) baseline, (B) response to intervention in old men compared to response to intervention in young men, and $(C)$ genes in old towards a young expression profile. (ZIP $4761 \mathrm{~kb}$ )

Additional file 4: Gene Set Enrichment Analysis outputs for (A) old men compared to young men before intervention, (B) response to intervention in young men, $(C)$ response to intervention in old men, and (D) response to intervention in old men compared to response to intervention in young men. (ZIP $75 \mathrm{~kb})$

Additional file 5: Ingenuity Pathway Analysis Upstream regulators output used for Additional file 1: Table S1 (A) baseline, (B) response to intervention in young men, and $(C)$ response to intervention in old men. (ZIP 27 kb)

\section{Abbreviations}

BMI: body mass index; CR: caloric restriction; GSEA: Gene Set Enrichment Analysis; PBMCs: peripheral blood mononuclear cells; RMA: Robust Multi-Array Average.

\section{Competing interests}

The authors declare that they have no competing interests.

\section{Authors' contributions}

CPGMG conceived and designed the experiments. JAS and IPGB performed the experiments. IPGB and LAA analysed the data. IPGB wrote the paper. MM and LAA critically revised the manuscript for important intellectual content. All authors read and approved the final manuscript.

\section{Acknowledgements}

We thank the participants, Mechteld Grootte-Bromhaar, Jenny Jansen, the nurses, and dieticians, for their practical work during the study. Furthermore, we thank Philip de Groot and Mark Boekschoten for helping with microarray analysis.

\section{Author details}

${ }^{1}$ Division of Human Nutrition, Wageningen University, Bomenweg 2, 6703 HD Wageningen, The Netherlands. ${ }^{2}$ Current Address: Norwich Medical School, University of East Anglia, Norwich NR4 7TJ, UK. ${ }^{3}$ Division of Human Nutrition, Wageningen University \& Research centre, PO BOX 8129, NL-6700 EV Wageningen, The Netherlands.

Received: 8 December 2015 Accepted: 19 April 2016

Published online: 06 May 2016

\section{References}

1. Bolstad BM, Irizarry RA, Astrand M, Speed TP. A comparison of normalization methods for high density oligonucleotide array data based on variance and bias. Bioinformatics. 2003:19(2):185-93.

2. Bouwens M, Afman LA, Muller M. Fasting induces changes in peripheral blood mononuclear cell gene expression profiles related to increases in fatty acid beta-oxidation: functional role of peroxisome proliferator activated receptor alpha in human peripheral blood mononuclear cells. Am J Clin Nutr. 2007:86(5):1515-23.

3. Caimari A, Oliver P, Keijer J, Palou A. Peripheral blood mononuclear cells as a model to study the response of energy homeostasis-related genes to 
acute changes in feeding conditions. OMICS. 2010;14(2):129-41. doi:10.1089/omi.2009.0092.

4. Castello L, Froio T, Cavallini G, Biasi F, Sapino A, Leonarduzzi G, et al. Calorie restriction protects against age-related rat aorta sclerosis. FASEB J. 2005; 19(13):1863-5. doi:10.1096/fj.04-2864fje.

5. Choi KM, Kwon YY, Lee CK. Characterization of global gene expression during assurance of lifespan extension by caloric restriction in budding yeast. Exp Gerontol. 2013;48(12):1455-68. doi:10.1016/j.exger.2013.10.001

6. Colman RJ, Anderson RM, Johnson SC, Kastman EK, Kosmatka KJ, Beasley $\mathrm{TM}$, et al. Caloric restriction delays disease onset and mortality in rhesus monkeys. Science. 2009;325(5937):201-4. doi:10.1126/science.1173635.

7. Crujeiras AB, Parra D, Milagro Fl, Goyenechea E, Larrarte E, Margareto J, et al. Differential expression of oxidative stress and inflammation related genes in peripheral blood mononuclear cells in response to a low-calorie diet: a nutrigenomics study. OMICS. 2008;12(4):251-61. doi:10.1089/omi.2008.0001.

8. Dai M, Wang P, Boyd AD, Kostov G, Athey B, Jones EG, et al. Evolving gene/ transcript definitions significantly alter the interpretation of GeneChip data. Nucleic Acids Res. 2005;33(20):e175. doi:10.1093/nar/gni179.

9. Davidson MB. The effect of aging on carbohydrate metabolism: a review of the English literature and a practical approach to the diagnosis of diabetes mellitus in the elderly. Metab Clin Exp. 1979;28(6):688-705.

10. de Magalhaes JP, Curado J, Church GM. Meta-analysis of age-related gene expression profiles identifies common signatures of aging. Bioinformatics. 2009;25(7):875-81. doi:10.1093/bioinformatics/btp073.

11. Fontana L, Meyer TE, Klein S, Holloszy JO. Long-term calorie restriction is highly effective in reducing the risk for atherosclerosis in humans. Proc Natl Acad Sci U S A. 2004;101(17):6659-63. doi:10.1073/pnas.0308291101.

12. Fontana L, Villareal DT, Weiss EP, Racette SB, Steger-May K, Klein S, et al. Calorie restriction or exercise: effects on coronary heart disease risk factors. A randomized, controlled trial. Am J Physiol Endocrinol Metab. 2007;293(1): E197-202. doi:10.1152/ajpendo.00102.2007.

13. Gerbase-DeLima M, Liu RK, Cheney KE, Mickey R, Walford RL. Immune function and survival in a long-lived mouse strain subjected to undernutrition. Gerontologia. 1975;21(4):184-202.

14. Gruver AL, Hudson LL, Sempowski GD. Immunosenescence of ageing. J Pathol. 2007;211(2):144-56. doi:10.1002/path.2104.

15. Holloszy JO, Fontana L. Caloric restriction in humans. Exp Gerontol. 2007; 42(8):709-12. doi:10.1016/j.exger.2007.03.009.

16. Hu S, Xie Z, Onishi A, Yu X, Jiang L, Lin J, et al. Profiling the human proteinDNA interactome reveals ERK2 as a transcriptional repressor of interferon signaling. Cell. 2009;139(3):610-22. doi:10.1016/j.cell.2009.08.037.

17. Irizarry RA, Bolstad BM, Collin F, Cope LM, Hobbs B, Speed TP. Summaries of Affymetrix GeneChip probe level data. Nucleic Acids Res. 2003;31(4):e15.

18. Jiang JC, Jaruga E, Repnevskaya MV, Jazwinski SM. An intervention resembling caloric restriction prolongs life span and retards aging in yeast. FASEB J. 2000;14(14):2135-7. doi:10.1096/fj.00-0242fje.

19. Masoro EJ. Overview of caloric restriction and ageing. Mech Ageing Dev. 2005;126(9):913-22. doi:10.1016/j.mad.2005.03.012.

20. Mattison JA, Roth GS, Beasley TM, Tilmont EM, Handy AM, Herbert RL, et al. Impact of caloric restriction on health and survival in rhesus monkeys from the NIA study. Nature. 2012. doi:10.1038/nature11432.

21. Mercken EM, Crosby SD, Lamming DW, Jebailey L, Krzysik-Walker S, Villareal $D$, et al. Calorie restriction in humans inhibits the PI3K/AKT pathway and induces a younger transcription profile. Aging Cell. 2013. doi:10.1111/acel.12088

22. Pallavi R, Giorgio M, Pelicci PG. Insights into the beneficial effect of caloric/ dietary restriction for a healthy and prolonged life. Front Physiol. 2012;3:318. doi:10.3389/fphys.2012.00318.

23. Park SK, Prolla TA. Lessons learned from gene expression profile studies of aging and caloric restriction. Ageing Res Rev. 2005;4(1):55-65. doi:10.1016/j.arr.2004.09.003.

24. Pawelec G. Immunosenescence comes of age. Symposium on aging research in immunology: the impact of genomics. EMBO Rep. 2007:8(3):220-3. doi:10.1038/sj.embor.7400922.

25. Plank M, Wuttke D, van Dam S, Clarke SA, de Magalhaes JP. A meta-analysis of caloric restriction gene expression profiles to infer common signatures and regulatory mechanisms. Mol Biosyst. 2012;8(4):1339-49. doi:10.1039/c2mb05255e.

26. Pletcher SD. The modulation of lifespan by perceptual systems. Ann N Y Acad Sci. 2009;1170:693-7. doi:10.1111/j.1749-6632.2009.04926.x.
27. Ribaric S. Diet and aging. Oxidative Med Cell Longev. 2012;2012:741468. doi:10.1155/2012/741468.

28. Shannon P, Markiel A, Ozier O, Baliga NS, Wang JT, Ramage D, et al. Cytoscape: a software environment for integrated models of biomolecular interaction networks. Genome Res. 2003;13(11):2498-504. doi:10.1101/gr. 1239303.

29. Smyth GK. Linear models and empirical Bayes methods for assessing differential expression in microarray experiments. Stat Appl Genet Mol Biol. 2004;3:Article3. doi:10.2202/1544-6115.1027.

30. Tumor Analysis Best Practices Working G. Expression profiling-best practices for data generation and interpretation in clinical trials. Nat Rev Genet. 2004;5(3):229-37. doi:10.1038/nrg1297.

31. Walker G, Houthoofd K, Vanfleteren JR, Gems D. Dietary restriction in C. elegans: from rate-of-living effects to nutrient sensing pathways. Mech Ageing Dev. 2005:126(9):929-37. doi:10.1016/j.mad.2005.03.014.

32. Weindruch R, Sohal RS. Seminars in medicine of the Beth Israel Deaconess Medical Center. Caloric intake and aging. N Engl J Med. 1997;337(14):986-94. doi:10.1056/NEJM199710023371407

33. Wen Z, Wang C, Shi Q, Huang Y, Su Z, Hong H, et al. Evaluation of gene expression data generated from expired Affymetrix GeneChip(R) microarrays using MAQC reference RNA samples. BMC Bioinformatics. 2010;11 Suppl 6: S10. doi:10.1186/1471-2105-11-S6-S10.

34. Winkels RM, Jolink-Stoppelenburg A, de Graaf $K$, Siebelink E, Mars M, de Groot L. Energy intake compensation after 3 weeks of restricted energy intake in young and elderly men. J Am Med Dir Assoc. 2011;12(4):277-86. doi:10.1016/j.jamda.2010.08.011.

\section{Submit your next manuscript to BioMed Central and we will help you at every step:}

- We accept pre-submission inquiries

- Our selector tool helps you to find the most relevant journal

- We provide round the clock customer support

- Convenient online submission

- Thorough peer review

- Inclusion in PubMed and all major indexing services

- Maximum visibility for your research

Submit your manuscript at www.biomedcentral.com/submit
BioMed Central 